\title{
Violências e afetos: intercâmbios sexuais e econômicos na (recente) produção antropológica realizada no Brasil*
}

\author{
Adriana Piscitelli ${ }^{* *}$
}

\section{Resumo}

Neste texto apresento uma leitura crítica de parte da recente produção antropológica sobre intercâmbios sexuais e econômicos, realizada no Brasil. Delineio primeiro alguns traços do contexto no qual foram realizados esses estudos. Considero depois aspectos marcantes dessa produção. Levo em conta a maneira como esses estudos incorporam diferentes dimensões de violência, como tratam das relações entre gênero e sexualidade e como analisam as articulações entre afetos e dinheiro no âmbito do sexo mercantilizado. Finalmente, realizo alguns comentários sobre as singularidades da produção brasileira, em termos da literatura internacional sobre esses temas.

Palavras-chave: Intercâmbios econômicos e sexuais, Prostituição, Gênero, Sexualidade, Violência.

\footnotetext{
* Recebido para publicação em 12 de fevereiro de 2014, aceito em 25 de abril de 2014.

** Pesquisadora do Núcleo de Estudos de Gênero - Pagu, Unicamp. piscitelliadriana@gmail.com
} 
Violence and Affects: Sexual and Economic Exchanges in the(recent) Anthropological Studies Carried in Brazil

\begin{abstract}
In this article I analyze part of the recent anthropological researches about sexual and economic exchanges carried in Brazil. Taking into account some aspects of the context in which these studies were conducted I consider how they incorporated different dimensions of violence, how they analyze the relations between gender and sexuality and the articulations between affects and money in the realm of commodified sex. Finally, I comment on the singularities of these studies in terms of the international literature about these exchanges.
\end{abstract}

Key Words: Sexual and Economic Exchanges, Prostitution, Gender, Sexuality, Violence 


\section{Introdução}

Neste texto apresento alguns comentários sobre parte da recente produção antropológica realizada no Brasil que analisa intercâmbios sexuais e econômicos. Presto particular atenção a pesquisas desenvolvidas a partir dos primeiros anos da década de 2000, quando o corpo de trabalhos nessa área aumentou de maneira expressiva no país. Não faço um levantamento exaustivo desse material. Levando em conta a proposta do dossiê para o qual foi preparado este artigo, reflito sobre as contribuições da produção antropológica sobre essa problemática em termos das reflexões sobre gênero e sexualidade, tomando como referência apenas alguns textos produzidos no âmbito dessa disciplina. Observo, porém, que embora a antropologia com sua longa tradição de reflexões sobre intercâmbios econômicos e de estudos etnográficos em profundidade contribua de maneira específica na produção de conhecimento sobre trocas sexuais e econômicas, esse corpo de estudos manteve um estreito diálogo com relevantes trabalhos realizados no âmbito de outras disciplinas, particularmente sobre prostituição, no país (Rago, 1991; Moraes 1996; Souza, 1998) ${ }^{1}$. E situo os textos aqui considerados no âmbito de aspectos que, do meu ponto de vista, são marcantes nos recentes trabalhos antropológicos sobre essa problemática. Refirome à crescente politização desse campo de estudos e à sua relação com os deslocamentos nos focos de análise dessas pesquisas e nas abordagens teóricas adotadas.

Os estudos antropológicos sobre essa problemáticas $e$ expandiram no âmbito da ampliação dos estudos sobre sexualidade no país, com algumas características particulares. Nesses anos, pesquisas sobre trocas sexuais e econômicas foram recorrentemente apresentadas em mesas redondas, simpósios e grupos de trabalho, em reconhecidas reuniões acadêmicas. No entanto, as reflexões baseadas nesses estudos tiveram uma ampla demanda extra-acadêmica por parte de diferentes instâncias do

\footnotetext{
1 Agradeço a atenta leitura e os comentários de Ana Fonseca e José Miguel Olivar.
} 
Estado, de agências multilaterais supranacionais e da sociedade civil organizada, incluindo organizações de prostitutas. O interesse dessas demandas esteve voltado, sobretudo, para questóes vinculadas ao turismo sexual, ao tráfico internacional de pessoas, aos casamentos associados aos mercados do sexo e à prostituição.

No contexto brasileiro, a expansão dessas pesquisas coincide com uma série de aspectos que confluíram,chamando a atenção para a prostituição e afetando seriamente o seu exercício. Parte significativa desses estudos reage a essa situação, está permeada pelo interesse em apoiar os direitos das trabalhadoras sexuais e dialoga de maneira crítica com políticas que têm restringido o sexo comercial e limitado as mobilidades das pessoas envolvidas em trocas sexuais e econômicas, no país e no exterior.

Uma leitura desses trabalhos sugere que esse embasamento político permeia a recente produção de conhecimento sobre intercâmbios sexuais e econômicos no Brasil. Ele se expressa em análises que, considerando a configuração de um campo acadêmico-político em torno da prostituição, concedem relevância à história e às reivindicações das organizações de prostitutas, ativas desde finais da década de 1980 no país (Tedesco, 2005; Simões, 2010b; Olivar, 2013). Esse embasamento é perceptível em estudos que se centram nas ações do Estado voltadas para o trabalho sexual e também nas de redes institucionais não estatais, como articulações feministas e/ou vinculadas a instituições religiosas, mediante as quais se consolidam e são legitimadas normas vinculadas à regulação do sexo comercial (Skackauskas, 2014; Tavares, 2014; Corrêa e Olivar, 2014). Ele está presente em pesquisas que levam seriamente em conta a operacionalização de disposições legais supranacionais relativas a questóes como o tráfico de pessoas, com efeitos restritivos nas atividades $e$ deslocamentos de trabalhadoras/es sexuais (Grupo Davida, 2005; Piscitelli, 2013; Lowenkron, 2012). Esse embasamento também permeia trabalhos que iluminam a diversidade de dinâmicas sociais e de dimensões de agência presentes nas trocas sexuais $e$ econômicas. Essas análises, ancoradas em trabalhos etnográficos, oferecem substantivas contribuições para a compreensão desses 
intercâmbios. Elas adquirem relevância política ao oferecer elementos para contrapor-se a um debate público no qual essa diversidade tende a ser apagada, mediante a evocação de uma ideia englobante de violência vinculada a esses intercâmbios. E, nesse percurso, essas pesquisas delineiam perspectivas inovadoras em termos analíticos.

Neste artigo realizo alguns comentários sobre esse conjunto de aspectos. Apresento primeiro um esboço do contexto no qual esses estudos foram realizados. Na sequência considero algumas características de parte dessa produção, levando em conta: (1) como ela foi incorporando a análise de diferentes dimensões de violência vinculadas às trocas sexuais e econômicas; (2) a contribuição desses estudos para a análise das relações entre gênero $e$ sexualidade $e$ (3) como neles são analisadas as articulações entre afetos e dinheiro no âmbito do sexo mercantilizado. Finalmente, considero a singularidade da produção antropológica realizada no Brasil em relação à literatura internacional sobre essa problemática. Os trabalhos realizados no país desafiam as fronteiras estabelecidas na produção internacional que, traçando limites entre as trocas sexuais $e$ econômicas em função dos seus graus de mercantilização, analisam separadamente as categorias delimitadas.

\section{Traços de um contexto}

No período aqui contemplado, diversos aspectos afetaram o exercício da prostituição no Brasil. A partir dos primeiros anos da década de 2000, no país, tem se difundido e capilarizado ${ }^{2}$ uma

${ }^{2}$ A criação de comitês estaduais e municipais de enfrentamento a esse crime e da realização de inúmeros cursos de capacitação e de campanhas conduziu à incorporação da problemática por diversos setores da sociedade. Esse processo tem sido alimentado por instâncias do Estado, movimentos sociais e organizações não governamentais e, em 2014, tem ampliado consideravelmente o seu alcance através da participação de setores religiosos, particularmente a Igreja Católica, mediante a Campanha da Fraternidade 2014, voltada para o combate ao tráfico humano. Apesar de ter alcances locais diferenciados, essa Campanha está 
discussão sobre tráfico de pessoas que, muitas vezes, tem confundido esse crime com o exercício da prostituição, alimentando a repressão dessa atividade $e$ restringindo a mobilidade das pessoas a ela vinculadas (Blanchette e Silva, 2011; Piscitelli, 2013). No entanto, no marco de alterações presentes no Código Penal relativas à prostituição, de um crescente neoabolicionismo que permeia as ações de alguns setores do movimento feminista $e$ das inquietações em relação aos grandes eventos esportivos que terão lugar no país ${ }^{3}$, a repressão à prostituição tem se disseminado mobilizando outros recursos retóricos, para além do tráfico de pessoas. Eles envolvem o turismo sexual e, sobretudo, a exploração sexual.

Acionar essas noções para coibir o exercício da prostituição não é algo novo. Ao longo da década de 2000 , essa mobilização tem sido registrada em diversos estudos acadêmicos no Brasil (Blanchette e Silva, 2011; 2005). No entanto, ela tem se intensificado no âmbito das operações de "limpeza" em diversas cidades, não desvinculadas de processos de gentrificação, realizadas no marco das preocupações pela realização da Copa do Mundo (Silva, Blanchette e Bento, 2013).

O termo exploração sexual está presente no Estatuto da Criança e do Adolescente/ECA, instituído em 1990, a partir de $2000^{4}$. Ele foi incorporado, introduzindo uma expressão utilizada, na década de 1980, em Convenções Internacionais, como a Convenção dos Direitos da Criança das Nações Unidas, de 1989 e disseminada entre ativistas (Landini, 2005). A introdução desse

propiciando a discussão sobre a problemática em paróquias disseminadas por todo o país (Conferência Nacional dos Bispos do Brasil, 2013).

3 Com forte ênfase, segundo Blanchette (2014), na 'higienização', na eliminação das prostitutas dos lugares públicos onde a mídia estrangeira pode vê-las, atualizando antigos procedimentos de "limpeza" que tiveram lugar em diversas cidades do país (Mazzariol, 1976; Simões, 2003; 2010; Olivar 2010/2013; Cavilha, 2010).

4 Art. 244-A. Submeter criança ou adolescente, como tais definidos no caput do art. $2^{\circ}$ desta Lei, à prostituição ou à exploração sexual (Incluído pela Lei $\mathrm{n}^{\circ}$ 9.975, de 23.6.2000). 
termo no ECA faz parte de uma (nova) regulamentação específica sobre a exploração sexual comercial de menores de idade (Lowenkron, 2012).

Nas leis brasileiras, o termo exploração sexual vinculado a pessoas maiores de 18 anos foi introduzido mais recentemente, nas alterações às leis do Código Penal realizadas em $2009{ }^{.5}$ Essa inclusão foi realizada em termos que, sem definir a exploração sexual, parecem tornar essa expressão equivalente à prostituição, porque ao tipificar crimes como o lenocínio e o tráfico de pessoas, as leis remetem o tempo todo à prostituição ou outra forma de exploração sexual. Essa palavra ou conduz a considerar que a prostituição está sendo pensada como uma modalidade de exploração sexual (Piscitelli, 2013). E a indefinição legal da noção de exploração sexual possibilita que ela seja lida, quando se trata de pessoas maiores de 18 anos, conforme diferentes interpretações: ora como prostituição forçada, ora como retenção de parte dos rendimentos das pessoas que exercem a prostituição, ou como lucro obtido pela intermediação, como indica a explicação do Conselho Nacional de Justiça reproduzida abaixo, difundida em 2014, acompanhando um cartaz contra o tráfico de pessoas, numa articulação que parece confundir diferentes sentidos.

5 (L-012.015-2009). Nessas modificações, os artigos voltados para a prostituição que, no passado estavam agrupados sob o título "Dos Crimes Contra os Costumes" passaram a ser incluídos no título "Dos Crimes Contra a Dignidade Sexual". Os artigos que, na versão de 1940, tratavam "Do Lenocínio e do Tráfico de Mulheres", a partir das alterações de 2005 passaram a tratar "Do Lenocínio e do Tráfico de Pessoas" e, em 2009, "Do Lenocínio e do Tráfico de Pessoa para Fim de Prostituição ou Outra Forma de Exploração Sexual". A partir das modificações de 2009, vários desses artigos (228; 229; 231 e 231a) passaram a referir-se à exploração sexual. 


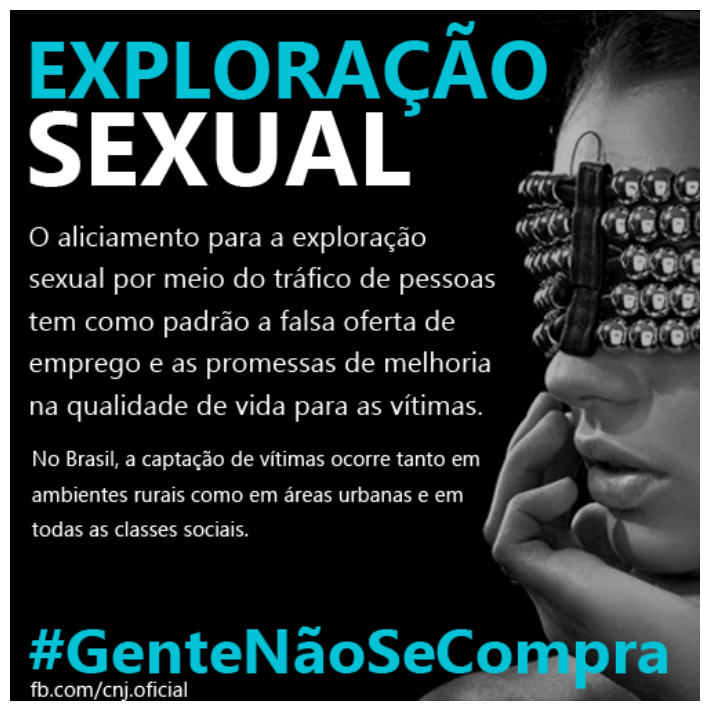

A exploração sexual é o meio pelo qual o indivíduo obtém lucro financeiro por conta da prostituição de outra pessoa, seja em troca de favores sexuais, incentivo à prostituição, turismo sexual, ou rufianismo. Isso é crime! Saiba mais no Código Penal: http://bit.ly/1dqm1Rx (CNJ, 30/05/2014). ${ }^{6}$

Indefinições legais e confusões conceituais contribuem para que essas três noções (tráfico de pessoas, turismo sexual $e$ exploração sexual) com frequência sejam consideradas como sinônimos. Essas ambiguidades também favorecem que a noção de exploração sexual seja pensada remetendo às novas configurações da sexualidade assinaladas por Carrara (2012), como expressão de violação do consentimento das pessoas que exercem a prostituição, justificando assim sua repressão (Lowenkron, 2013; 2013b). Esse movimento se vê favorecido, no Brasil, pela rápida disseminação de posições feministas neoabolicionistas, que atualizam noções presentes nas campanhas realizadas em países europeus, a partir da segunda metade do século XIX, para abolir a regulamentação da prostituição.

6 Postado na página do facebook do CNJ. 
Essas posições, trocando os antigos argumentos vinculados à moralidade, ao pecado e à lascívia por outros, associados à violência contra as mulheres, pensam a prostituição como símbolo da violência sexista, formando parte de um continuum que se inicia na publicidade, continua nos espetáculos, inclui a pornografia e culmina na prostituição. Nessa linha de pensamento, a prostituição é exploração sexual porque nela se obtém prazer sexual mediante a utilização abusiva da sexualidade de uma pessoa, anulando os seus direitos à dignidade, igualdade, autonomia e bem estar. Essa versão de abolicionismo nega qualquer forma de prostituição livre e o direito a prostituir-se, percebido como contrário aos direitos humanos universais. Por esse motivo, o abolicionismo radical pretende penalizar o cliente, culpável de violentar os direitos humanos das mulheres (Maqueda Abreu, 2009).

Análises da história recente do feminismo no Brasil sugerem que ele está distante de ser marcado por uma tradição abolicionista radical, tendo tido em alguns momentos, a partir da "segunda onda", aproximações com as prostitutas. Anos atrás, alguns autores consideravam que esses feminismos mostravam uma heterogeneidade de posições em relação ao exercício do trabalho sexual e mostravam poucas manifestações do abolicionismo radical (Corrêa e Olivar, 2014; Piscitelli, 2013c). A partir de 2012, porém, as manifestações abolicionistas se intensificaram, tornando-se crescentemente visíveis em organizações articuladas com redes feministas transnacionais, mas também em setores feministas de partidos políticos e em manifestações de jovens feministas que se consideram radicais e se apresentam como "radfems", inclusive no âmbito de reunióes acadêmicas, conforme observarmos nas duas imagens embaixo. 


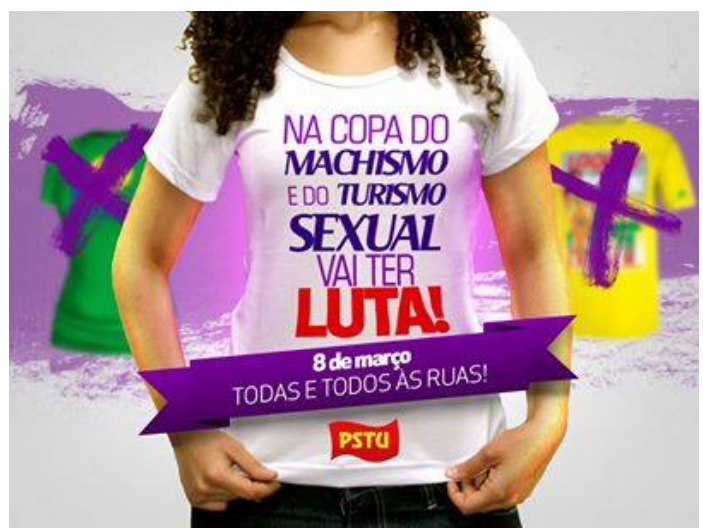

Imagem difundida pelo PSTU (Partido Socialista dos Trabalhadores Unificado), fazendo uma chamada para a comemoração do Dia Internacional da Mulher de 2014.

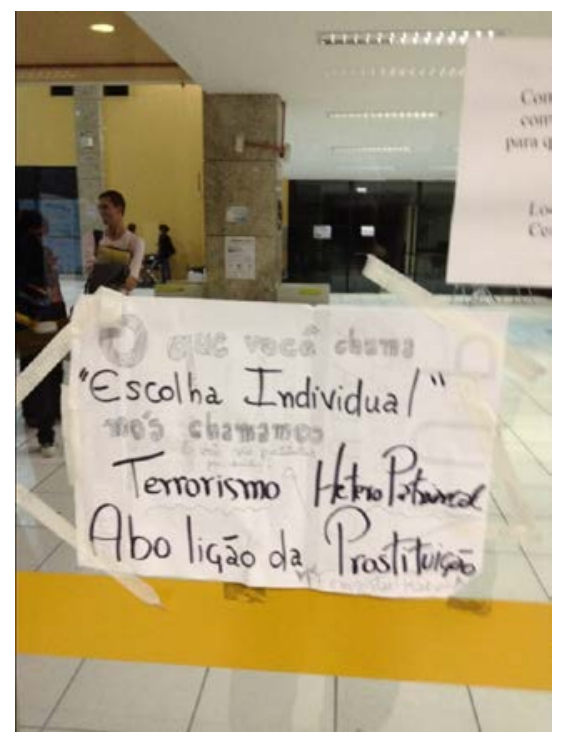

Cartaz colocado por jovens feministas no corredor de acesso à sala onde funcionou um grupo de trabalho sobre prostituição no Encontro Fazendo Gênero X, 2013 na Universidade Federal de Santa Catarina. Fotografia de Thaddeus Blanchette. 
No marco do avanço político da advocacy, com traços abolicionistas, voltada para a eliminação da "exploração sexual" e do tráfico de pessoas foram criados diversos pânicos vinculados aos deslocamentos de população nas fronteiras, à construção de grandes obras $e$ aos grandes eventos esportivos. Essas preocupações também vêm provocando reações contrárias que, embora atomizadas ${ }^{7}$, se difundem no âmbito nacional evocando, em ocasiões, situações de combate. Em blogs e jornais de ampla circulação, intelectuais e jornalistas questionam os pressupostos presentes nas posições abolicionistas (Capriglione, 2014; Calligaris, 2014). Deixando clara sua visão da Copa do Mundo, uma organização de prostitutas chamou a atenção, no Brasil e no exterior, por oferecer cursos de inglês para que as trabalhadoras sexuais tivessem melhores condições para atender os clientes estrangeiros durante esse evento (Folha de S. Paulo, 08/01/2013). Várias dessas organizações, associadas à Rede Brasileira de Prostitutas, estão preparando, em diversas partes do país, eventos promovendo discussões sobre a regulamentação da prostituição $e$ comemorando o Puta Dei - Dia Internacional da Prostituta - (Blog das Esquinas, 24/05/2013; Correio Popular, 30/05/2014; Revista Brasileiros, 01/06/2014). ${ }^{8}$ E organizações que aglutinam jovens feministas, como alguns coletivos da Marcha das Vadias ${ }^{9}$, apoiam as reivindicações dos direitos das prostitutas e/ou tentam incluir as

${ }^{7}$ Agradeço a José Miguel Olivar por ter contribuído com esta reflexão, assim como por ter chamado minha atenção para parte do material de mídia citado neste texto.

8 Ver: <http://blogdasesquinas.wordpress.com/2013/05/24/pega-fogo-cabareconvocatoria-para-artistas-puta-dei-2013/>,

<http://correio.rac.com.br/_conteudo/2014/05/capa/campinas_e_rmc/179184puta-dei-discute-a-regulamentacao-das-prostitutas.html >;

$<$ http://www.revistabrasileiros.com.br/2012/06/01/prostitutas-do-para-pedemregulamentacao-da-profissao-no-puta-dei/\#.U4o6HCinta4>, consultados em maio de 2014.

9 As Marchas das Vadias se multiplicaram pelo Brasil nos últimos três anos, mas cada marcha realizada em âmbito local é organizada por coletivos que se constituem de modo autônomo uns em relação aos outras, com diferentes composições e posicionamentos políticos 
problemáticas que as afetam com outras mais amplas, como as que vivem os habitantes das periferias (Tavares, 2014).

Delinear traços desse contexto é relevante, pois a recente produção antropológica sobre intercâmbios econômicos e sexuais se produziu no marco dessas divergências e em diálogo com elas. Nesse âmbito, no qual parte expressiva dos estudos realizados adquire um caráter explicitamente político, essa produção passa a levar seriamente em conta diversas dimensões de violência que afetam as trabalhadoras sexuais.

\section{Violências}

Nos estudos antropológicos pioneiros sobre prostituição, que hoje são praticamente considerados clássicos no Brasil, são registradas algumas dimensões de violência. No entanto, nessas pesquisas, esse tema não adquire relevância em termos analíticos.

Na dissertação de mestrado de Regina Mazzariol, defendida na Unicamp em 1976, são descritos aspectos que podem ser vinculados à violência de Estado. A autora analisa a prostituição feminina em Campinas no âmbito da "Operação Limpeza", que a deslocou do centro da cidade para uma zona relativamente distante, num processo de confinamento. ${ }^{10} \mathrm{Na}$ segunda metade da década de 1960, nessa cidade, a prostituição foi conduzida para o Jardim Itatinga, uma região próxima do aeroporto de Viracopos. Mazzariol, sem necessariamente utilizar o termo violência, descreve a coação e intimidações exercidas nesse processo sobre as prostitutas, incluindo as coerções para a realização compulsória de fichamentos e exames médicos $e$ as prisões arbitrárias às quais foram submetidas. A dissertação apresenta uma rica descrição, baseada em documentos, de diversos aspectos envolvendo as ações de policiais e as decisões dos juízes. A principal linha de análise, orientada pelas formulações de Mary Douglas, está voltada, sobretudo, para a compreensão da relação entre noções de limpeza e sujeira que permeiam esse processo de confinamento.

${ }^{10}$ Sob a orientação de Peter Fry. 
Na década de 1980, alusões à maneira como os policiais tratavam as prostitutas ou à violência ocasionalmente presente nas relações prostituta/clientes são registradas em três importantes publicações sobre a problemática: o estudo de Jefferson Afonso Bacelar (1982), baseado numa pesquisa realizada no final da década de 1970, sobre famílias de prostitutas na região do Pelourinho, em Salvador, e os livros produzidos a partir das dissertações de Maria Dulce Gaspar (1985), sobre prostituição feminina em Copacabana ${ }^{11}$, e de Nestor Perlongher (1987), sobre prostituição masculina no centro de São Paulo ${ }^{12}$. No entanto, a violência está longe de adquirir um lugar de destaque nesses estudos.

No estudo de Bacelar há referências aos policiais militares, tidos como perversos e malvados, no depoimento de uma prostituta. O livro de Gaspar dedica alguns parágrafos à relevância que as garotas de programa concedem à potencial violência por parte de clientes e considera as estratégias por elas utilizadas para proteger-se dela. E, sem negar a existência dessa violência, a autora desloca a análise para considerar os motivos que conduzem à produção de um discurso nativo das prostitutas que associa prostituição e violência. Perlongher (1987:115) trata de maneira mais direta dos diferentes graus de violência presentes no universo dos michês por ele estudados que "parece crescer enquanto a origem social desce". Essa violência, vinculada pelo autor à delinquência e aos roubos cometidos pelos michês, é por eles exercida sobre os clientes.

Parece-me que, até recentemente, nos estudos antropológicos sobre prostituição realizados no Brasil existia uma reticência em conceder destaque às dimensões de violência presentes na vida das/os trabalhadores sexuais. Um dos motivos talvez tenha sido o esforço por distanciar-se das leituras sobre prostituição que a percebem como inerentemente violenta. Refiro-me às formulações de autoras que, afinadas com o

\footnotetext{
${ }^{11}$ Orientada por Gilberto Velho, defendida no Museu Nacional em 1984.

${ }^{12}$ Orientada por Mariza Corrêa, defendida na Unicamp em 1986.
} 
pensamento abolicionista, consideram a prostituição como caso extremado do exercício abusivo do sexo e a prostituta como vítima de violência, um objeto sexual, um ser passivo e carente de poder (MacKinnon, 1982; Barry, 1997). A rejeição suscitada por esse posicionamento poderia explicar o motivo pelo qual trabalhos que, no Brasil, não se alinham com essas perspectivas foram relativamente reticentes no que se refere a tratar da violência à qual estão submetidas as prostitutas. ${ }^{13}$

No período contemplado neste artigo, ao contrário, estudos antropológicos sobre trocas sexuais e econômicas realizados no país concedem importância às diversas dimensões de violência que permeiam essas relações. Esse movimento é visível em estudos ancorados em abordagens que, rejeitando posições abolicionistas, questionam a ideia da violência como englobante das relações sociais no universo desses intercâmbios. Essas pesquisas consideram os efeitos nas vidas das/os trabalhadores sexuais das ações do Estado e de outras instâncias que operam nos processos de governança no âmbito nacional e também de instituições que regulam a conduta de estados e pessoas num plano transnacional.

A violência de Estado adquire relevância no trabalho de Olivar (2013) sobre políticas dirigidas à prostituição de rua $e$ sobre as experiências de trabalhadoras sexuais que se tornaram ativistas em prol dos direitos das prostitutas. Analisando as trajetórias de quatro dessas mulheres, em Porto Alegre, a partir da década de 1980, o autor mostra o peso dessa violência em

\footnotetext{
${ }^{13}$ Vale observar que essa reticência também está presente em parte da produção internacional. Alguns trabalhos, que definem a violência como atos que restringem o desenvolvimento ou a integridade física, psicológica, intelectual ou emocional dos indivíduos, consideram que ela está presente em todas as relações que as prostitutas estabelecem no local de trabalho e também fora dele (Ribeiro e Sacramento, 2005). No entanto, linhas de abordagem contrárias descrevem situações análogas praticamente evitando o termo violência. Assim, ambientes de trabalho marcados por roubos e pelo uso de armas de fogo, abusos realizados por clientes, acosso policial e pela hostilidade de outras trabalhadoras sexuais aparecem em itens como "condições de trabalho e problemas" (Antonius-Smits et al., 1999).
} 
suas experiências cotidianas. ${ }^{14}$ Ora vinculada aos métodos de negociação com cafetões e traficantes, ora voltada para outras prostitutas, ora perpetrada pela policia civil, ora pela policia militar, a violência manifesta-se em reiteradas arbitrariedades, detenções ilegais, surras e estupros, chegando a incorporar requintadas e brutais torturas.

A violência policial também adquire importância na reconstrução histórica realizada por Soraya Simões sobre a prostituição no Rio de Janeiro (2010b) e no recente trabalho de Aline Tavares (2014) sobre as dinâmicas de poder presentes no Jardim Itatinga e Campinas. A etnografia realizada pela autora nessa zona, mais de 30 anos depois do estudo de Mazzariol (1976), situa a violência da Policia Militar no marco de complexas distribuições de poder num local no qual adquirem importância as redes criminosas organizadas: "as pessoas do bang", envolvidas com as atividades de tráfico de drogas, roubo e assassinatos. A autora situa nesse contexto a violência da polícia militar, em 2013, com nítidas conotações sexistas, que envolveu o estabelecimento de um "estado de sítio" com duração de vários dias, espancamentos $e$ torturas contra moradores do bairro $e$ trabalhadoras sexuais, com particular crueldade com travestis, cárcere privado e omissão de socorro. Nesse estudo, assim como no trabalho de Olivar, a violência de Estado voltada para as trabalhadoras sexuais é localizada no âmbito de um intricado campo político. E os dois autores destacam as reações das organizações de prostitutas a essa violência. Nessas reações, aliás, as organizações de trabalhadoras sexuais parecem consolidar suas próprias agendas políticas.

Paralelamente, trabalhos recentes mostram a violência simbólica que permeia as ações de diferentes redes sociais $e$ institucionais que colaboram na consolidação de regras e normas vinculadas ao sexo comercial. Alguns consideram as práticas de não reconhecimento das prostitutas em certos setores do

${ }^{14}$ A violência policial contra as prostitutas em Porto Alegre também é considerada na dissertação de mestrado de Letícia Tedesco (2008). 
feminismo no Brasil, crescentemente marcados pelo pensamento abolicionista (Corrêa e Olivar, 2013; Piscitelli, 2013c). ${ }^{15}$ Outros estudos, como o de Andreia Skackauskas (2014) mostram como essa violência permeia as relações entre trabalhadoras sexuais $e$ integrantes de organizações de "resgate" de prostitutas, vinculados à Igreja Católica. Essa pesquisa ilumina o processo de subalternização de prostitutas que mostram desacordos com os métodos mediante os quais a Pastoral da Mulher Marginalizada pretende mudar a vida dessas mulheres ("reabilitação, recuperação, ressocialização"), através do procedimento de deixálas falar, mas sem ouvi-las.

A violência vinculada às disposições de instituições que regulam a conduta de estados e pessoas num plano transnacional adquire relevância em estudos que consideram as mobilidades vinculadas aos mercados do sexo, principalmente de pessoas que oferecem serviços sexuais. Parte significativa desses trabalhos é realizada numa perspectiva que leva em conta as articulações entre Estado e sociedade civil, considerando as configurações de ambos numa leitura transnacional. Refiro-me a uma abordagem que leva em conta a relevância de instâncias supranacionais na regulação da conduta dos Estados e a importância das redes de grupos de ativistas que, centrados em temas específicos, exercem pressão transnacional sobre estados nacionais $e$ ativismos locais (Sharma e Gupta, 2006).

Nesse marco, são analisadas as ações restritivas em termos de mobilidades ancoradas em elaborações nacionais de disposições legais supranacionais voltadas para o tráfico de pessoas, considerando os seus efeitos sobre os deslocamentos de pessoas envolvidas no sexo comercial no Brasil e sobre brasileiras, mulheres e travestis, no exterior (Teixeira, 2008; Silva, Blanchette e Bento, 2013; Goulart, 2011). Esses estudos também concedem

\footnotetext{
${ }^{15} \mathrm{~A}$ importância do feminismo no apoio a políticas punitivas que atingem $e$ extrapolam a prostituição tem sido considerada na produção internacional (Bernstein, 2012). A produção brasileira, porém, também mostra as alianças criativas e positivas de alguns setores dos feminismos jovens, em relação às prostitutas (Tavares, 2014).
} 
importância à violência de Estado, particularmente de outros estados nacionais, que se materializa nos maus tratos $e$ humilhações, frequentemente acompanhados por deportações, aos quais são submetidos migrantes irregulares que exercem a prostituição, por agentes da polícia migratória, no exterior (Piscitelli, 2013).

Nas recentes pesquisas antropológicas sobre intercâmbios econômicos e sexuais realizadas no Brasil também são consideradas outras dimensões de violência, que têm lugar na intimidade, dentro e fora do âmbito laboral, nas relações com clientes ou com namorados ou cônjuges. Nesses estudos se considera a violência perpetrada por "gigolôs", num passado recente (Tedesco, 2008; Olivar, 2013). Essas pesquisas também consideram a violência exercida por clientes, sobre a qual voltarei em seguida. No momento, me interessa observar que, longe de considerar essa última modalidade de violência algo inerente à prostituição, esses estudos situam essas agressões no marco político no qual a prostituição é exercida. Assim, esses episódios de violência são considerados como expressão da falta de segurança vinculada ao estatuto não regulamentado, marginalizado $e$ estigmatizado dessa atividade, que se agrava de maneira aguda em contextos migratórios, particularmente quando as pessoas que oferecem serviços sexuais são migrantes irregulares.

Nesses estudos também recebe atenção a violência material e/ou simbólica que permeia, em ocasiões, as relações amorosas $e$ conjugais de mulheres que oferecem serviços sexuais ou que foram trabalhadoras sexuais no passado. Abordagens que concedem peso equivalente ao trabalho sexual como lugar de socialidades e de operação de relações de poder e consideram como ele se imbrica em diversas relações, incluindo a conjugalidade, mostram como nessas articulações as relações assimétricas podem ser negociadas, mas isso não exime as prostitutas da violência física e/ou simbólica (Olivar, 2013). Às vezes essa violência está vinculada às tensões que, na articulação entre trabalho sexual e casamento, são suscitadas pela exigência de diferentes qualidades morais para diferentes classes de intimidade 
sexual (Zelizer, 2009), que podem tornar insustentável a posição de prostituta e esposa (Piscitelli, 2013).

Assim, um dos deslocamentos nos focos de análise das recentes pesquisas realizadas no Brasil consiste na atenção concedida a essas diversificadas dimensões de violência. Essa atenção, porém, não pode ser desvinculada da conformação de um campo acadêmico-político de estudos sobre intercâmbios sexuais e econômicos. A ativa participação nesse campo tem estimulado abordagens que, enfrentando posições abolicionistas a partir de outras leituras (também feministas) sobre gênero, sexualidade e desejo, sobre poder e agência/agency, consideram o sexo como um lugar de disputas e situam o trabalho sexual no contexto de processos de governança (no âmbito nacional $e$ supranacional) e exploram suas articulações com outros aspectos do social.

\section{Gênero, sexualidade e outras categorias de diferenciação}

Nesse conjunto de trabalhos, alguns estudos sobre intercâmbios sexuais e econômicos mostram caminhos promissores em termos de tornar mais complexas as discussões sobre gênero e sexualidade. Essas pesquisas apresentam material que se distancia das posições "tradicionais" na prostituição, do homem cliente e da mulher prestadora de serviços. Esses estudos mostram a participação das mulheres como empresárias nos mercados do sexo, particularmente em zonas, em diferentes cidades brasileiras (Pasini, 2005; Simões, 2010; Tavares, 2014; Tedesco, 2008). Neles, à presença de homens no lado da oferta de serviços sexuais para outros homens, já considerados no estudo de Perlongher (1987), somaram-se as travestis. Na primeira metade da década de 1990, Hélio Silva defendeu sua dissertação no Museu Nacional, ${ }^{16}$ sobre travestis, na Lapa, no Rio. Na década de 2000 há uma proliferação de trabalhos sobre a participação delas, as travestis, nos mercados do sexo, no Brasil e no exterior (Pelúcio, 2009; Patrício, 2008; Teixeira, 2008), oferecendo serviços

${ }^{16}$ Orientado por Rubem César Fernandes. 
sexuais e, também, às vezes, como empresárias na indústria do sexo (Piscitelli, 2013).

O conjunto desses estudos é sugestivo, em termos das relações que estabelecem entre gênero e sexualidade no âmbito da oferta e consumo de sexo, particularmente quando se presta atenção a como eles tratam da violência entre as prestadores/as de serviços sexuais e consumidores/as. Parte importante dessa produção presta séria atenção às interseccionalidades entre categorias de diferenciação. Em um momento teórico marcado pela tendência a considerar como gênero se articula com outras distinções na produção de desigualdades é possível perceber mais uma vez o pioneirismo do trabalho de Perlongher (1987), que já concedia atenção a diversas diferenças (gênero, sexualidade, classe social e "cor") presentes na conformação do desejo no universo dos michês paulistanos. A operação dessas categorias de diferenciação adquire centralidade nos recentes estudos, particularmente na crescente produção voltada para a análise da participação de brasileiras/os nos mercados transnacionais do sexo.

A presença de estrangeiros consumidores de sexo no Brasil é registrada já na pesquisa de Bacelar, de finais da década de 1970 (1982). Nas narrativas das prostitutas com as quais ele trabalha está presente a relevância que os gringos tinham, já naquele período, para as mulheres do Pelourinho, que entesouravam fotografias $e$ as cartas de amor que eles lhes enviavam. Uma de suas entrevistadas lhe mostra a fotografia de um inglês, com quem ela morou três meses $e$ as cartas de um holandês, que em inglês declarava: "I love you". No entanto, o autor não articula questões vinculadas à nacionalidade ou à raça na análise. A preocupação por essas articulações aparece mais tarde, a partir de inícios da década de 2000, em análises centradas no turismo sexual no Brasil e nas mobilidades de trabalhadoras sexuais brasileiras no exterior, que consideraram as particularidades adquiridas pelas intersecções entre gênero, sexualidade, idade, "raça", classe e nacionalidade no jogo de demanda e oferta de sexo em diferentes contextos (Piscitelli, 2004; Pelúcio, 2011; Da Silva, 2011; Maia, 2011; Moutinho, neste dossiê). 
Ao tratar da violência entre prestadoras/res de serviços sexuais e clientes, sobretudo nas pesquisas sobre homens que oferecem serviços sexuais para outros homens e sobre travestis, porém, gênero tende a aparecer como a distinção central. No entanto, nesses trabalhos, as pessoas situadas em posições inferiores $e$ alvo de violência não são necessariamente aquelas situadas no lado da oferta, como geralmente sucede nas análises sobre mulheres prostitutas (Fonseca, 2004; Pasini, 2005). Nas pesquisas sobre homens que oferecem serviços sexuais para outros homens e sobre travestis, as pessoas situadas em posições inferiores, estigmatizadas e alvo de violência tendem a ser aquelas que destoam das normas de gênero, tanto no lado da oferta como no do consumo de serviços sexuais. São os homens "feminilizados", como alguns clientes de prostituição masculina (Carrara e Vianna, 2006). E trata-se também das travestis que, situadas no lado da oferta de serviços sexuais, embaralham atributos de gênero. As travestis, aliás, parecem condensar diferentes dimensões de violência; além de aparecerem como alvo preferencial nas ruas e de suscitar agressões mais virulentas por parte da polícia (Tavares, 2014), atraem também a violência dos potenciais consumidores de sexo. No caso delas, as desigualdades vinculadas a outras diferenças, como idade, raça e nacionalidade, quando se trata de migrantes no exterior, podem intensificar a fragilidade de suas posições sociais, mas não aparecem como as mais relevantes (Teixeira, 2008).

Essas pesquisas ainda não contemplam as trocas entre homens que oferecem serviços sexuais em setores altamente mercantilizados dos mercados do sexo heterossexuais $e$ as consumidoras desses serviços. No entanto, os estudos realizados no Brasil têm considerado relacionamentos que envolvem trocas sexuais e econômicas entre homens de regiões pobres do país e mulheres, turistas de países "ricos" (Piscitelli, 2011; Cantalice, 2011).

Um aspecto a ser destacado é que o deslocamento das mulheres para o lugar de consumidoras de sexo tem provocado discordâncias analíticas. A produção sócioantropológica internacional sobre turistas estrangeiras à procura de sexo mostra 
essas divergências. As discrepâncias residem na força diferenciada atribuída a outras categorias de diferenciação, como nacionalidade, classe e "raça", que expressam privilégios estruturais, e assim neutralizariam as desigualdades vinculadas ao gênero. Em um extremo, essas leituras consideram que as desigualdades de gênero são englobantes e apagam os privilégios associados a "raça", classe e nacionalidade, uma vez que em função do Patriarcado, as mulheres sempre ocupam posições subordinadas (Jeffreys, 2003). No outro extremo, considera-se que os privilégios que possibilitam a essas mulheres consumir sexo permeado por fantasias racializadas do exotismo, as "masculiniza": à maneira dos turistas sexuais, essas mulheres objetificariam e explorariam sexualmente os homens locais (Kempadoo 1999; O'Connell Davidson e Sanchez Taylor, 1999). E no centro há posições nuançadas, nas quais o poder conferido por esses privilégios é percebido como abrindo caminho para o ensaio de novos repertórios de gênero que, no entanto, não chegam a romper inteiramente com noções de feminilidade "ocidentais" (Pruitt e Lafon, 1995; Jacobs, 2009; Frohlick, 2013).

Nos estudos sobre turistas estrangeiras à procura de sexo no nordeste do Brasil que estabelecem intercâmbios sexuais $e$ econômicos, marcados pela ambiguidade, com homens locais, racializados e sexualizados, os privilégios dessas mulheres em termos de nacionalidade, classe e "raça" parecem neutralizar as desigualdades vinculadas a gênero. Nessas pesquisas, que prestam atenção às percepções dos caça-gringas (Cantalice, 2011) e às experiências de estrangeiras (Piscitelli, 2011), a violência não parece atingir as estrangeiras situadas do lado da demanda, enquanto elas são turistas, com recursos e ampla mobilidade espacial. A violência afeta, mas apenas temporariamente, àquelas mulheres que estabelecem relacionamentos duradouros e/ou casam com homens locais $e$, abandonando o estatuto de turistas, se convertem em esposas-residentes. Nesse processo, as tensões eclodem quando elas passam a ser englobadas por códigos locais de gênero e sexualidade. 
Esse conjunto de trabalhos sugere que, no âmbito da demanda e oferta de serviços sexuais, o deslocamento das mulheres para o lugar de consumidoras de sexo, como turistas, não aparece como um escândalo equivalente, em termos das articulações entre gênero e sexualidade, àquele representado por clientes feminilizados e por travestis prestadoras de serviços sexuais.

\section{Afetos e dinheiro no âmbito do sexo mercantilizado}

Parte expressiva da literatura sócio-antropológica internacional sobre trabalho sexual realizada a partir da década de 1990 tende a tratar essa atividade articulada basicamente à economia e a ideologias sobre a sexualidade, mas de maneira relativamente autônoma de outros domínios do social. Explicome. Estudos que se tornaram praticamente "clássicos" para as seguintes gerações de pesquisadores se centraram nas relações de poder que permeiam diversas modalidades de prostituição; no estilo de trabalho envolvido nos serviços sexuais; nos motivos pelos quais o trabalho sexual provoca rejeição e nas respostas das organizações de prostitutas. Esses trabalhos consideraram diversos fatores vinculados a essa atividade, principalmente a articulação entre a precariedade social, agravada no âmbito das migrações $e$ os crescentes lucros obtidos pela indústria do sexo, mudanças nas percepções da sexualidade e alterações nos estilos de lazer (Enloe, 1989; O'Connell Davidson, 1998; Chapkis, 1997; Kempadoo e Doezema, 1998; Kempadoo, 1999). No entanto, esses trabalhos raramente analisam como os intercâmbios sexuais e econômicos, entranhados no social, se articulam com outras dimensões, altamente relevantes em diversos contextos, como o parentesco.

Nesses estudos que estou considerando "clássicos", os afetos tendem a ser pouco considerados. ${ }^{17} \mathrm{O}$ interesse por esse

${ }^{17}$ Nas décadas de 1980 e 1990, os afetos aparecem, sobretudo, em estudos voltados para a transnacionalização dos mercados do sexo que analisam modalidades de turismo sexual, marcadas por ambiguidades. Nessas pesquisas, mulheres de países ricos à procura de sexo aparecem estabelecendo relações com parceiros de regiões pobres do mundo que, desde o ponto de vista delas, estão marcadas por afetos (Pruitt e Lafont, 1995). Em escala infinitamente 
tema se dissemina a partir da década de 2000, em análises sobre sexo comercial muitas vezes influenciadas pelas formulações de Zelizer (2009) relativas às articulações entre dinheiro, interesses $e$ sentimentos no âmbito da intimidade. Em parte desses trabalhos o amor é tratado como uma performance que, encobrindo a natureza da relação, contribui para seduzir consumidores de sexo (Brennan, 2004). Outros estudos não consideram essas performances como estratégias para enganar os clientes, mas restringem o alcance de sua autenticidade. ${ }^{18}$ Uma linha diferente de trabalhos segue um caminho mais fértil, em termos analíticos. Distanciando-se de discussões sobre a autenticidade dos sentimentos, esses estudos exploram como o amor se torna um aspecto integral das negociações em relacionamentos frequentemente assimétricos e como as narrativas sobre ele adquirem sentido no âmbito de diversos processos sociais, incluindo a transnacionalização dos mercados do sexo (Constable, 2009; Faier, 2007; Cheng, 2013). No entanto, o foco desses estudos tende a restringir-se ao âmbito laboral.

Paralelamente, outros estudos analisam intercâmbios sexuais e econômicos considerando como eles estão entranhados em diversas dimensões do social e simultaneamente tratam o amor como um problema analítico. Essas pesquisas, porém, não analisam a prostituição, mas o sexo transacional (transactional sex) e tático (tactical sex) ${ }^{19}$, isto é, modalidades de trocas que são

menor, esses sentimentos são associados a homens que viajam a procura de sexo (Cohen, 1986).

${ }^{18}$ Nas modalidades de serviços sexuais analisadas por Bernstein (2007) em cidades pós-industriais de países do Norte, parte significativa de uma nova variedade de trabalho sexual consistiria em oferecer e consumir conexão emocional e física temporária, que evoca a ideia de "afeto autêntico", mas é explicitamente delimitada pelo acerto comercial.

${ }^{19} \mathrm{Na}$ sua análise das economias afetivas do turismo heterossexual em Cuba e a República Dominicana, Amalia Cabezas (2009) conceitualiza o sexo tático como a utilização do sexo para aliviar as penúrias econômicas, sem eliminar o prazer, o companheirismo e a amizade. Ela, porém, distancia esses intercâmbios sexuais e econômicos do trabalho sexual, uma vez que o sexo tático remete a uma atividade flexível, contingente e temporária e não se encaixa nas categorias 
diferenciadas do trabalho sexual (Hunter, 2002; 2010; Cabezas, 2009). Trata-se de estudos realizados em regiões do mundo consideradas pobres, principalmente no Caribe e, sobretudo na África. A noção de sexo transacional foi utilizada, aliás, para destacar a centralidade dos intercâmbios materiais nas relações sexuais nesses contextos, evitando confundir uma diversidade de formas de intimidade com a prostituição $e$ afastando essas modalidades de intimidade das conotações estigmatizantes que afetam à prostituição. ${ }^{20}$

A noção de sexo transacional tem sido criticada por tornar esses intercâmbios em algo dicotômico, uma vez que as pessoas que neles participam estariam motivadas apenas em função de dois motivos: a luta pela sobrevivência ou o desejo de consumo (Stoebenauet al, 2011). Essa conceitualização também tem sido problematizada por destacar a mercantilização da sexualidade de mulheres subalternizadas, sem levar em conta o poder do erotismo feminino e como esse erotismo se conecta com dinâmicas de gênero, moralidades de intercâmbio e também parentesco ${ }^{21}$ (Groes-Green, 2013). No entanto, o que me interessa destacar é que esses estudos analisam como trocas marcadas pela pobreza $e$ por inseguranças se imbricam em diferentes dimensões do social $e$, ao mesmo tempo, exploram os estilos de afetos que as permeiam, levando em conta como as emoções estão entrelaçadas com práticas culturais e condições materiais que

existentes de trabalho sexual comercial, como a prostituição, nem produz subjetividades que remetam ao exercício dessa atividade.

${ }^{20} \mathrm{Na}$ formulação de Mark Hunter, esse termo remete a trocas nas quais os participantes não se percebem como prostitutas e clientes e o intercâmbio de presentes por sexo é parte de um conjunto mais amplo de obrigações, que evocam reciprocidade, em relações desiguais, muitas vezes permeadas por afetos que remetem ao amor material, que pode surgir do coração e também ser promovido pelo dinheiro.

${ }^{21} \mathrm{~A}$ partir de um estudo de caso em Moçambique, o autor mostra a ativa participação das redes de parentesco femininas no treinamento erótico das jovens. Esse treinamento e técnicas de sedução possibilitam relações de sexo transacional que redundam em benefício do sustento das redes de parentesco dessas jovens. 
participam na constituição de subjetividades e tornam possíveis tipos particulares de relações (Cole e Thomas, 2009).

Sintetizando, nesse conjunto de trabalhos há uma nítida separação entre os estudos voltados para o trabalho sexual e aqueles que analisam modalidades de sexo transacional. Nesses últimos parecem concentrar-se as análises de intercâmbios sexuais $e$ econômicos percebidos como intimamente entrelaçados com outras dimensões do social $\boldsymbol{e}$ permeados por sentimentos. Nesse ponto, a produção antropológica sobre intercâmbios sexuais $e$ econômicos realizada no Brasil apresenta algumas singularidades.

Os estudos realizados no Brasil mostram como essas trocas, inclusive a prostituição, se conectam com uma trama ampla $e$ densa de relações sociais, permeadas por afetos, que extrapolam o âmbito laboral. Nesse sentido, o trabalho de Claudia Fonseca (1996; 2004), que toma como referência a prostituição de rua exercida por mulheres em Porto Alegre, é pioneiro. Na trilha aberta por essa autora, outros estudos sublinharam a dificuldade de separar trabalho e família, prostituição, lar $e$ as formas de proteção e dominação, atravessadas por sentimentos, às vezes paixões, que existem no âmbito do parentesco, considerando os arranjos domésticos, afetivos e laborais que articularam "gigolôs" e suas múltiplas mulheres na Porto Alegre das décadas de 1980 e 1990 (Tedesco, 2008; Olivar, 2011; 2013).

O trabalho de Fonseca (1996) também é relevante no que se refere a mostrar a proximidade e as diferenças da prostituição, no sentido de intercâmbio direto de dinheiro por serviços sexuais, com outras trocas sexuais e econômicas que evocam a ideia de sexo transacional, envolvendo presentes e benefícios em troca de sexo (como os oferecidos pelo velho que ajuda) nas quais se envolvem as prostitutas. A distinção entre diferentes modalidades de trocas sexuais e econômicas já estava presente no belo estudo de Bacelar. Descrevendo o cotidiano da família de uma prostituta no Maciel, na região do Pelourinho, em Salvador, no final da década de 1970, o autor mostra como, paralelamente às visitas dos clientes recebidos em casa, as prostitutas também recebiam homens com os quais estabeleciam outras modalidades de trocas, 
"ajudando-as": nos termos de um desses homens: “... eu não deixo de ajudar... Cr $\$ 100.00$ a Cr $\$ 150$, por semana, fora o gás e outros trocados" (Bacelar, 1982:164).

O trabalho de Claudia Fonseca, porém, chama a atenção para as trocas sexuais e econômicas análogas nas quais se envolvem mulheres que não exercem a prostituição $e$ fazem parte das mesmas camadas sociais das prostitutas. Esse estilo de trocas $e$ os afetos que os permeiam são registrados há tempo na produção antropológica brasileira, em estudos que não estão centrados no sexo comercial e consideram as experiências de mulheres de grupos populares que trabalham como empregadas domésticas ou são amantes de homens casados (Paim, 1998; Brites, 2000) ${ }^{22} \mathrm{~A}$ particularidade do trabalho de Fonseca é que mostra a relevância das trocas sexuais e econômicas nos grupos de camadas populares,prostitutas ou não, e integra num mesmo estudo as duas modalidades de intercâmbios (programas, como é popularmente denominada a prostituição no Brasil e ajuda), chamando a atenção sobre o envolvimento das prostitutas com ambas.

$\mathrm{Na}$ recente produção realizada no Brasil sobre esses intercâmbios, a atualização do interesse por analisar as articulações entre sexo mercantilizado e afetos conduziu a repensar as fronteiras associadas a esse tipo de sexo. Essas pesquisas exploraram a coexistência $e$ a distinção entre uns $e$ outros tipos de trocas ${ }^{23}$ e o trânsito que as pessoas realizam entre elas, analisando o lugar $e$ o estilo dos afetos nesses intercâmbios em relacionamentos com brasileiros/as e estrangeiros/as, no Brasil, e no exterior (Pasini, 2000; Pereira, 2010; França, 2011; Luna Sales, 2013; Blanchette e da Silva; Piscitelli, 2007; Maia, 2011), no âmbito de

\footnotetext{
${ }^{22}$ Eles também são considerados na produção antropológica recente que trata de jovens migrantes em Portugal, originários em camadas populares no Brasil (Togni, 2014) e sobre mulheres brasileiras em prisões catalãs (Padovani, 2013).

${ }^{23}$ Vale observar que se o programa evoca um contrato de serviços, não necessariamente isento de afetos, a ajuda está inserida em uma tradição de intercâmbios hierárquicos e frequentemente remete a noções de amparo, cuidado e afeto, que se expressam em termos de contribuição para a sobrevivência econômica e para o consumo (Piscitelli, 2011).
} 
trocas que envolvem mulheres, homens e travestis (Pelúcio 2011; Teixeira 2011). Essas análises orientaram a formulação de noções, como a de "mercados do sexo", que permitiram contemplar essa diversidade de intercâmbios (Piscitelli, Assis e Olivar, 2011).

Aqui vale um esclarecimento. Há diversas acepções do termo mercado. Esse termo, segundo Eva Illouz (1997), pode remeter: à organização das relações sociais constitutivas da esfera da produção, ao âmbito no qual tem lugar o consumo e ao terreno abstrato do intercâmbio de bens. As duas primeiras acepções remetem à ideia de economia de mercado. Certamente, o conjunto de trocas sexuais e econômicas consideradas tem lugar no âmbito dessa economia, marcada pela expansão da cultura pública do sexo comercial. ${ }^{24}$ No entanto, a ideia de "mercados do sexo" proposta, está vinculada com a última acepção, remetendo a um universo amplo de intercâmbios sexuais e econômicos, materiais e simbólicos. A ideia é que, em contextos nos quais há uma longa história de interpenetrações entre economia $e$ sexualidade e nos quais há múltiplas manifestações de comércio e dádiva, muitas vezes entrelaçados, os intercâmbios sexuais $e$ econômicos podem se materializar em relações mais completamente mercantilizadas, como os programas, que em alguns países são vinculados à indústria do sexo (Lim, 2004). No entanto, as trocas sexuais e econômicas também se materializam em outras modalidades de intercâmbios. Observo que conceitualizações análogas estão presentes no trabalho de outros antropólogos. Christian Groess (2013), trabalhando na África, utiliza o termo economias sexuais para referir-se a esse diversificado universo de trocas entranhadas no social como economias sexuais. No entanto, ao trabalhar no âmbito dessas economias, $\mathrm{o}$ autor se centra especificamente no sexo transacional. Nesse sentido, a particularidade dos estudos

\footnotetext{
${ }^{24}$ Segundo Bernstein (2007), essa expansão inclui a ampliação na produção de pornografia, a normalização de produtos sexuais comerciais para consumidoras, como os analisados por Gregori (2010), incluindo lingerie, brinquedos sexuais e vídeos educativos, e ainda a popularização do gênero literário das memórias das trabalhadoras sexuais.
} 
realizados no Brasil é que analisam conjuntamente umas e outras modalidades de trocas, considerando a relativa fluidez entre elas.

Na recente produção antropológica sobre esses intercâmbios realizada no Brasil, estudos como o de Gomes Pereira (2010) consideram os estilos de afeto neles presentes, reiterando ideias sobre os sentimentos delineados em etnografias sobre camadas populares. Refiro-me a traçar distinções entre os sentimentos associados a estratégias para a reprodução social $e$ às obrigações familiares, vinculados aos grupos populares, e os afetos presentes nas camadas médias urbanas, nos quais haveria maior incidência da noção de "amor romântico", pensado como arena de autorealização e prazer. No entanto, outros estudos mostram como, na trama de interesses, afetos e sexo presentes nessas trocas, programas, ajudas e namoros são atravessados por sentimentos que não podem ser linearmente vinculados ao "tipo" de intercâmbio envolvido (Piscitelli, 2011; Pelúcio, 2011; Teixeira, 2011). Além disso, emoções românticas, como paixões de cinema, e sentimentos considerados mais serenos, ancorados na valorização do companheirismo e na solidariedade "convivem" no horizonte emocional das pessoas entrevistadas, inclusive entre aquelas originárias de setores populares no Brasil.

As análises sobre os sentimentos presentes nesses estudos problematizam as separações entre estilos de amor vinculados a diferentes classes sociais presentes em trabalhos da antropologia brasileira. No entanto, eles também se distanciam das leituras sobre o amor alocadas ao Brasil na produção internacional. Nessa última, a ideia é que o amor romântico é parte de uma tradição Ocidental, entendida como Euro-Estadunidense, que apenas no âmbito da recente globalização se expandiu nesses setores sociais no Brasil, possibilitando que agora essas pessoas amem de uma maneira não apenas mais moderna e mais urbana, mas também "mais Ocidental" (Padilha et alii, 2007) ${ }^{25}$ Levando em conta a argumentação de Sérgio Costa (2005), é possível questionar o viés eurocêntrico mediante o qual é visto o amor romântico nessa

${ }^{25}$ Um viés análogo está presente nos estudos sobre África, ver Cole e Thomas, 2009. 
leitura, considerando-o resultado de processos de transmissão cultural exclusivos de sociedades europeias ocidentais. De acordo com o autor, o romantismo europeu fundiu e entrelaçou tradições culturais, imagens, lendas e fantasias amorosas de diversas partes do mundo, que chegavam à Europa por meio dos relatos de viagem $e$ das experiências coloniais. $\mathrm{E}$, ao mesmo tempo, lugares supostamente não ocidentais difundem ideais de amor, que circulam de maneira descentrada pelo mundo, através de diferentes meios (exemplos seriam as telenovelas latinoamericanas e o cinema de Bollywood).

Nesse sentido, a recente produção antropológica sobre intercâmbios sexuais e econômicos produzida no Brasil sugere que as emoções permeando relacionamentos que nasceram em processos de erotização da desigualdade, sexualizada $e$ racializada, no confronto com as manifestações empíricas da pobreza, e num diálogo intercultural, alimentam a elaboração de novas conceitualizações de amor, em pessoas originárias de países do Norte. Vale aqui remeter ao relato de um entrevistado de Susana Maia (2011:376-378), sobre os seus sentimentos em relação a uma garota morena de Cidade de Deus que conheceu no âmbito do turismo sexual no Rio. Ele visita a favela. Na pobreza, no cheiro dos esgotos a céu aberto, no desconforto de ver uma familia de sete pessoas apinhada num quarto, sente uma dimensão de humanidade que nunca tinha percebido antes $e$ passa a se sentir responsável por essa garota, expressando essa preocupação no envio de dinheiro. Ele não quer casar, porque não acredita no amor, mas sente que é a primeira vez na vida que está fazendo algo significativo por outra pessoa. E acaba refletindo: "se amor é como gostar, se importar se ela está bem, se ela vive ou morre, eu acho que eu amo ela".

Assim, neste corpo de estudos, as fronteiras em termos de análise estabelecidas em parte significativa da produção internacional que se centra ora no trabalho sexual, ora no sexo transacional se diluem. Essas pesquisas também problematizam as divisões existentes no que se refere aos sentimentos e estilos de amor e, através de um diálogo com conceitos próximos da 
experiência (Geertz, 2000), elaboram e exploram novas formulações analíticas.

\section{Considerações finais}

Considerando os estudos sobre mercantilização da intimidade, Nicole Constable (2009) observa que analisar a mercantilização não (deveria) ser um fim em si mesmo. No entanto, a mercantilização da intimidade oferece um precioso ponto de partida para as análises de relações sociais permeadas por gênero, de significados culturais, de desigualdades e de transformações sociais.

Essas análises estão sendo ensaiadas nos recentes estudos antropológicos sobre intercâmbios sexuais e econômicos realizados no Brasil. Esse crescente corpo de estudos, marcado pela preocupação em relação à agência das pessoas que se envolvem nessas trocas, apresenta uma diversidade de estudos de caso, com forte ênfase na transnacionalização dos "mercados do sexo". Cabe considerar quais são os caminhos possíveis para ampliar a produção de conhecimento nessa área.

Uma via possível é a ampliação de recortes empíricos. Num momento no qual países que atraíam migrantes vinculados a esses mercados sofrem os efeitos de severas crises econômicas, trabalhadoras sexuais brasileiras perdem o interesse em deslocarse ao exterior (Tavares, 2014) e, ao contrário, o Brasil atrai novos fluxos de população, vale ampliar as leituras sobre a transnacionalização desses mercados no âmbito do país. E, em uma conjuntura na qual as discussões sobre tráfico de pessoas $e$ sobre o controle de fluxos de população se voltam para as fronteiras nacionais, cabe considerar os efeitos desse debate nos territórios transfronteirizos, uma tarefa que apenas foi iniciada (Olivar, 2013b). As reflexões sobre as relações entre gênero e sexualidade presentes nesses intercâmbios certamente adquiririam maior alcance através de pesquisas sobre as dinâmicas envolvendo homens que oferecem serviços sexuais em setores mercantilizados dos mercados do sexo heterossexuais e mulheres 
consumidoras desses serviços. Finalmente, considerando que as trocas sexuais e econômicas têm sido analisadas tomando como referência, sobretudo, setores de camadas populares, num movimento que tende a sexualizar e a tornar exóticas as desigualdades e ao mesmo tempo apaga os intercâmbios que têm lugar nas camadas superiores, cabe explorar as características $e$ dinâmicas dessas trocas, particularmente o sexo transacional, em outras camadas sociais.

Essa ampliação de recortes abriria caminhos para aprofundar nos avanços analíticos de um campo acadêmicopolítico fervilhante $e$ altamente promissor, em termos de problematizações teóricas, com singularidades no que se refere à produção internacional sobre essas problemáticas.

\section{Referências bibliográficas}

ANTONIUS-SMITS, Christel et alii. Gold and Commercial Sex, Exploring the Link between Small-scale Gold Mining and Commercial Sex in the Rainforest of Suriname. In: KEMPADOO, Kamala (ed.). Sun, sex, and gold. Tourism and Sex Work in the Caribbean. New York, Rowman and Littlefield Publishers, 1999, pp.237-263.

BACElAR, Jeferson Afonso. A família da prostituta. São Paulo. Editora Ática, 1982.

BARRY, Kathleen. Prostitution of sexuality: a cause for new international human rights. Journal of Loss and Trauma (2:1), 1997, pp.27-48.

BERSTEIN, Elizabeth. Temporarily Yours. Intimacy, Authenticity and the Commerce of Sex. Chicago, The University of Chicago Press, 2007.

BERSTEIN, Elizabeth. Carceral politics as gender justice? The "traffic in women" and neoliberal circuits of crime, sex, and rights. Theory and Society, 2012. DOI 10.1007/s11186-012-9165-9.

BLANCHETTE, Thaddeus. "Fariseus" e "gringos bons": masculinidade e turismo sexual em Copacabana. In: PISCITELl, Adriana; AssIS, Gláucia Oliveira e OLIVAR, José Miguel Nieto. Gênero, sexo, amor e dinheiro: mobilidades transnacionais envolvendo o Brasil. CampinasSP, Núcleo de Estudos de Gênero-PAGU/Unicamp, 2011, pp.57-103. 
BlAnChETTE, Thaddeus. El pánico moral del Mundial. Entrevista realizada por Wellington Castilho para o CLAN, 22/06/2014. Disponível em: http://www.clam.org.br/es/destaque/conteudo.asp?cod=11622\#.U6a 9VdABoZc.facebook.

BlanchetTe, Thaddeus e Silva, Ana Paula de. O mito de Maria, uma traficada exemplar: confrontando leituras mitológicas do tráfico com as experiências de migrantes brasileiros, trabalhadores do sexo, Revista Interdisciplinar da Mobilidade Humana, vol. 19, $\mathrm{n}^{\circ}$ 37, Brasília-DF, Centro Scalabriniano de Estudos Migratórios, 2011, pp.79-105.

BRENNAN, Denise. What's Love Got to do with it? Transnational Desires and Sex Tourism in the Dominican Republic. Durham, Duke University Press, 2004.

BRITES, Jurema. Afeto, desigualdade e Rebeldia. Bastidores do serviço doméstico. Tese de Doutorado, PPGAS, Universidade Federal do Rio Grande do Sul, Porto Alegre, 2000.

CABEZAS, Amalia. Economies of Desire. Sex and Tourism in Cuba and the Dominican Republic. Philadelphia, Temple University Press, 2009.

Calligaris, Contardo. O Prazer ainda é um escândalo. Folha de São Paulo, 31 de maio de 2014. Disponível em: $<$ http://www1.folha.uol.com.br/colunas/contardocalligaris/2013/09/13 36787-o-prazer-ainda-e-um-escandalo.shtml>

CANTAliCE, Tiago. Turismo, sexo e romance: caça-gringas da Praia da Pipa - RN. In: PISCITELLI, Adriana, AsSIS, Gláucia Oliveira e OlIVAR, José Miguel Nieto. Gênero, sexo, amor e dinheiro: mobilidades transnacionais envolvendo o Brasil. Campinas-SP, Núcleo de Estudos de Gênero-PAGU/Unicamp, 2011, pp.141-185.

CAPRIGlione, Laura. As prostitutas da Copa e as de sempre. Yahoo, notícias, 20 de mai de 2014. Disponível em: https://br.noticias.yahoo.com/blogs/laura-capriglione/prostitutas-dacopa-e-sempre-030520177.html.

CARRARA, SÉRgIO. Sexualidade E Moralidades: A Emergência dos Direitos Sexuais. Instituto de Filosofia e Ciências Humanas da Unicamp, Campinas, SP, 17 De Maio De 2012. 
CARRARA, Sérgio e VIANNA, Adriana R. B. Lethal violence against travestis in Rio de Janeiro city. Physis vol.16, n 2, 2006, pp.233-249. [online]

CHAPKIS, Wendy. Live Sex Acts. Women Performing Erotic Labour. Londres, Cassell, 1997.

CHENG, Sealing. Labor of Love: The Sex Worker and the Anti-trafficking Advocate. Texto apresentado no IASSCS IX 2013 "Sex and the Marketplace: What's Love got to do with it?”, Buenos Aires, 2013.

COHEN, Erik. Lovelorn farangs: the correspondence between foreign men and Thai girls. Anthropological Quarterly, vol. 59, n 3, July 1986, pp.115-127.

COLE, Jennifer e THOMAS, Lynn. Love in Africa. Chicago, The University of Chicago Press, 2009.

CONFERÊNCIA NACIONAL DOS BISPOS DO BRASIL. Campanha da fraternidade 2014, Manual. Brasília, Edições CNBB, 2013.

CONSTABLE, Nicole. The Commodification of Intimacy: Marriage, Sex and Reproductive Labour. Annual Review of Anthropology (38), 2009, pp.49-64. Disponível em: $<$ http://www.annualreviews.org/journal/anthro > .

CORRÊA, Sonia e OlIVAR, José Miguel Nieto. The politics of prostitution in Brazil between "state neutrality" and "feminist troubles". In: MURTHY, Laxmi e SESHU Meena Saraswathi (eds.). The Business of Sex, New Delhi, 2014.

Costa, Sergio. Amores Fáceis: Romantismo e consumo na identidade tardia. Novos Estudos CEPRAP (73), São Paulo, CEBRAP, 2005, pp.112-124.

DA SILVA, Ana Paula. "Cosmopolitismo tropical": uma análise preliminar do turismo sexual internacional em São Paulo. In: PISCITELLI, Adriana, Assis, Gláucia Oliveira e OlIVAR, José Miguel Nieto. Gênero, sexo, amor e dinheiro: mobilidades transnacionais envolvendo o Brasil. Campinas, SP, Núcleo de Estudos de GêneroPAGU/ Unicamp, 2011, pp.103-141.

ENLOE, Cynthia. Bananas, beachesand bases. Making feminist sense of International Politics. Berkeley, University of California Press, 1989. 
FAIER L. Filipina migrants in rural Japan and their professions of love. Journal of the American Ethnological Society 34, Malden, Blackwell Publishing, 2007, pp.148-62.

FONSECA, Cláudia. A dupla carreira da mulher prostituta. Revista Estudos Feministas, n 1, Rio de Janeiro, 1996, pp.7-33.

FONSECA, Cláudia. A morte de um gigolô: fronteiras da transgressão e sexualidade nos dias atuais. In: PISCITELLI, Adriana; GREGORI, Maria Filomena e CARRARA, Sergio. Sexualidades e Saberes, Convenções e Fronteiras Rio de Janeiro, Garamond, 2004, pp.257-283.

FRANÇA, Marina Veiga. Dentro de fora do programa: interações afetivosexuais de prostitutas da zona boêmia de Belo Horizonte. $35^{\circ}$ Encontro Anual da ANPOCS, Caxambu-MG, outubro de 2011.

FroHlick, Susan. Sexuality, Women and Tourism. Cross-border desires through contemporary travel. New York, Routledge, 2013.

GASPAR, Maria Dulce. Garotas de programa. Prostituição em Copacabana e Identidade Social. Zahar, 1985.

GEERTZ, Clifford. O saber local: novos ensaios em antropologia interpretativa. Petrópolis, Vozes, 2000.

GOMES PEREIRA, Amanda. "Um bonde chamado afeto": descrevendo as conexões numa casa de prostituição feminina. Dissertação de Mestrado. Programa de pós-graduação em ciências sociais, Juiz de Fora, UFJF, 2010.

GOULART CARRIJO, Gilson. Imagens em trânsito: narrativas de uma travesti brasileira. In: PISCITELLI, Adriana; ASSIS, Glaucia de Oliveira e OlIVAR, José Miguel Nieto. Gênero, sexo, amor e dinheiro: mobilidades transnacionais envolvendo o Brasil. Campinas, SP, Núcleo de Estudos de Gênero-Pagu/Unicamp, 2011, pp.263-321.

GREGORI, Maria Filomena. Prazeres Perigosos. Erotismo, gênero e limites da sexualidade. Tese de livre docência defendida no Instituto de Filosofia e Ciências Humanas, UNICAMP, 2010.

Groes-GreEN, Christian. "To put men in a bottle": Eroticism, kinship, female power, and transactional sex in Maputo, Mozambique. American Ethnologist, vol. 40, n 1, Wiley, 2013, pp.102-117. 
GRUPO DAVIDA. Prostitutas, "traficadas" e pânicos morais: uma análise de produção de fatos em pesquisas sobre o "tráfico de seres humanos". Cadernos Pagu (25), Campinas, SP, Núcleo de Estudos de GêneroPagu/Unicamp, 2005, pp.153-185.

HUNTER, Mark. The materiality of Everyday Sex: thinking beyond "prostitution". African Studies (61), Taylor and Francis, 2002, pp.99120. [on line]

HUNTER, Mark. Love in the Time of Aids. Inequality, gender and Rights in South Africa. Bloomington, Indiana University Press, 2010.

Illouz, Eva. Consuming the Romantic Utopia, Love and the Cultural Contradictions of Capitalism. University of California Press, 1997

JEFFREYS, Sheila. Sex tourism: do women do it too? Leisure Studies, 22, Taylor and Francis, 2003, pp.223-238. [on line]

JACOBS, Jessica. Have sex will travel: romantic "sex tourism" and women negotiating modernity in the Sinai. Gender, Place and Culture 16(1), Taylor and Francis, 2009, pp.43-61. [on line]

KemPADOO, Kamala, DoEZEMA, Jo. Global Sex Workers. Rights, Resistance and Redefinition. New York, Routledge, 1998.

Kempadoo, Kamala. Sun, Sex and Gold, Tourism and Sex Work in the Caribbean. Lanham, Rowman and Littlefield, 1999.

KempadoO, Kamala. Sexingthe Caribbean. Gender, Race and Sexual Labour. Abingdon, Routledge, 2004.

LANDINI, Tatiana. Child sexual exploitation in Southeastern Brazil. Paper apresentado no Childhoods 2005 - Children and Youth in Transforming and Emerging Societies International Conference. Oslo, 29 de junho a 3 de julho, 2005.

LiM, Lin Leann. El sector del sexo: la contribución económica de una industria. In: OSBORNE, Raquel. (ed.) Trabajadoras del sexo: derechos, migraciones y tráfico en el siglo XXI. Barcelona, Ediciones Bellaterra, 2004, pp.57-85.

Losso, Juliana Cavilha Mendes. Dos desregramentos da carne. Um estudo antropológico sobre os itinerários urbanos, territorialidades, saberes e fazeres de profissionais do sexo em Florianóplis/SC. Tese de 
doutorado, Programa de Pós-graduação em Antropologia Social da Universidade Federal de Santa Catarina, 2010.

LOWENKRON, Laura. O monstro contemporâneo: a construção social da pedofilia em múltiplos planos. Tese de Doutorado, Programa de pósgraduação em Antropologia, Museu Nacional, 2012.

LOWENKRON, Laura. All against pedophilia: Ethnographic notes about a contemporary moral crusade. Vibrant, vol.10, Brasília-DF, 2013, pp.39-72.

LOWENKRON, Laura. Consentimento e vulnerabilidade: alguns cruzamentos entre o "abuso sexual infantil" e o "tráfico de pessoas para fim de exploração sexual". Grupo de Trabalho "sexualidades que confrontan", na X Reunión de Antropología Del Mercosur (RAM), Córdoba (Argentina), 2013b.

LUNA SALES, Ana Paula. Amor à venda? Ritualizações do programa entre as prostitutas do restaurante Granada, Etnográfica, vol. 17, n 1 , Lisboa, fev. 2013, pp.147-163.

MAIA, Suzana. Cosmopolitismo, desejo e afetos: sobre mulheres brasileiras e os seus amigos transnacionais. In: PISCITELLI, Adriana; Assis, Glaucia de Oliveira e OLIVAR, José Miguel Nieto. Gênero, sexo, amor e dinheiro: mobilidades transnacionais envolvendo o Brasil. Campinas, SP, Núcleo de Estudos de Gênero-Pagu/Unicamp, 2011, pp.363-385.

Magueda Abreu, Maria Luisa. Prostitución, feminismos y derecho penal. Granada, Editora Comares, 2009.

MAZZARIOL, Regina. "Mal Necessário", ensaio sobre o confinamento da prostituição na cidade de Campinas. Dissertação de mestrado, Programa de pós-graduação em antropologia social, Universidade Estadual de Campinas, 1976.

MACKINNON, Catherine. Marxism, feminism and the State: Toward Feminist Jurisprudence. Signs 7.5, Chicago, The University of Chicago Press, 1982, pp.515-544.

MorAES, Aparecida Fonseca. Mulheres da Vila. Editora Vozes, 1996.

O'Connell Davidson, Julia. Prostitution, Power and Freedom. Ann Arbor, The University of Michigan Press, 1998. 
O'CONNELl DAVIDSON, Julia e SANCHEZ TAYLOR, Jacqueline. Fantasy Islands. Exploring the Demand for sex Tourism. In: KEMPADOO, Kamala. Sun, Sex and Gold, Tourism and Sex Work in the Caribbean. Maryland, Rowman and Littlefield, 1999, pp.37-55.

Olivar, José Miguel Nieto. Banquete de homens: sexualidade, parentesco e predação na prática da prostituição feminina. Revista Brasileira de Ciências Sociais vol.26, n.75, São Paulo, fev. 2011. Disponível em: <http://dx.doi.org/10.1590/S010269092011000100005>.

Olivar, José Miguel Nieto. Políticas da prostituição de rua na experiência de quatro mulheres militantes. Rio de Janeiro, EDUERJ/CLAM, 2013.

Olivar, José Miguel Nieto. Mercados do sexo em territórios transfronteiriços: gênero e circulações na fronteira Brasil-Colômbia. Relatório final de pós-doutorado apresentado à Fapesp, 2013b.

PADILLA, Mark et alii (eds). Love and Globalization. Transformations of Intimacy in the Contemporary World. Naschville, Vanderbilt University Press, 2007.

PADOVANI, Natália Corazza. Confounding Borders and Walls: Documents, letters and the governance of relationships in São Paulo and Barcelona prisons. Vibrant - Virtual Brazilian Anthropology, vol. 10, $\mathrm{n}^{\circ}$ 2, jul-dez 2013. Brasília, ABA. Disponível em: $<$ http://www.vibrant.org.br/issues/v10n2/natalia-corazza-padovaniconfounding-borders-and-walls/ $>$.

PAIM, Heloísa Helena Salvatti. Vivendo como amante de um homem casado: entre a legitimidade $e$ a ilegitimidade das uniões extraconjugais. Dissertação de mestrado, Universidade Federal do Rio Grande do Sul, 1998.

PASINI, Elisiane. Corpos em evidência, pontos em ruas, mundos em pontos: a prostituição na região da Rua Augusta em São Paulo. Dissertação de mestrado, Programa de pós-graduação em antropologia. Universidade Estadual de Campinas, 2000.

PASINI, Elisiane. Os homens da Vila: um estudo de relações de gênero num universo de prostituição feminina. Tese de doutorado, Doutorado em Ciências Sociais, Universidade Estadual de Campinas, 2005. 
PEGA fogo cabaré convocatoria para artistas puta dei. Blog das esquinas, 24 de maio de 2013. Disponível em: $<$ http://blogdasesquinas.wordpress.com/2013/05/24/pega-fogocabare-convocatoria-para-artistas-puta-dei-2013/>.

PELÚCIO, Larissa. Abjeção e desejo, uma etnografia travesti sobre o modelo preventivo de Aids. Annablume, 2009.

PereirA, Amanda Gomes. "Um bonde chamado afeto": Descrevendo as conexões numa casa de prostituição feminina. Dissertação de mestrado, Programa de pós-graduação em ciências sociais, Universidade Federal de Juiz de Fora, 2010.

Perlongher, Nestor. O Negócio do Michê. A prostituição viril. São Paulo, Editora Brasiliense, 1987.

PisCITELli, Adriana. On Gringos and Natives, gender and sexuality in the context of international sex tourism. Vibrant - Virtual Brazilian Anthropology, ano 1, $\mathrm{n}^{\circ}$ 1, Brasília, 2004. Disponível em: $<$ http://seer.cfh.ufsc.br/index.php/vibrant/article/viewArticle/241>.

PisCITElli, Adriana. "Gringas ricas": Viagens sexuais de mulheres europeias no Nordeste do Brasil. Revista de Antropologia, vol 58 (3), 2011, pp.79-117.

PISCITELLI, Adriana. Trânsitos. Brasileiras nos mercados transnacionais do sexo. Rio de Janeiro, CLAM/EDUERJ, 2013a.

PISCITELLI, Adriana. Exploração sexual, trabalho sexual: noções e limites. In: SILVA, Daniele Andrade da et alii. Feminilidades: corpos $e$ sexualidades em debate. Rio de Janeiro, Eduerj, 2013b, pp.147-165.

PISCITElli, Adriana. Tensões, tráfico de pessoas, prostituição $e$ feminismos no Brasil. In: FELDMAN BIANCO, Bela. Desafios da antropologia brasileira. Associação Brasileira de Antropologia, 2013c, pp.109-152. Disponível em: <www.abant.org.br > .

PISCITElli, Adriana, Assis, Glaucia de Oliveira e OlIVAR, José Miguel Nieto. Introdução: transitando através de fronteiras. In: PISCITELLI, Adriana, ASSIS, Gláucia Oliveira e OlIVAR, José Miguel Nieto. Gênero, sexo, amor e dinheiro: mobilidades transnacionais envolvendo o Brasil. Campinas-SP, Núcleo de Estudos de GêneroPAGU/Unicamp, 2011, pp.5-31. 
PROSTITUTAS de $\mathrm{BH}$ têm aulas grátis de inglês para se preparar para a copa. Folha de S. Paulo, 8 de maio de 2013. Disponível em: $<$ http://www1.folha.uol.com.br/cotidiano/2013/01/1211528prostitutas-de-bh-tem-aulas-gratis-de-ingles-para-se-preparar-para-acopa.shtml>.

PROSTITUTAS do Pará pedem regulamentação da profissão no puta dei. Revista Brasileiros, $1^{\circ}$ de junho de 2012. Disponível em: $<$ http://www.revistabrasileiros.com.br/2012/06/01/prostitutas-dopara-pedem-regulamentacao-da-profissao-no-putadei/\#.U4o6HCinta4>.

PRUITT, Deborah, LAFONT, Suzanne. For Love and money. Romance Tourism in Jamaica. Annals of Tourism Research, vol. 22, $\mathrm{n}^{\circ} 2$, Elsevier, 1995, pp.422-440.

PUTA dei discute a regulamentação das prostitutas. Correio Popular, 30 de maio de 2014 . Disponível em: <http://correio.rac.com.br/_conteudo/2014/05/capa/campinas_e_rmc/ 179184-puta-dei-discute-a-regulamentacao-das-prostitutas.html $>$.

RAGO, Margareth. Os prazeres da noite. Prostituição e códigos da sexualidade feminina em São Paulo, 1890-1930. São Paulo, Paz e Terra, 1991.

RIBEIRO Fernanda Maria Vieira. Táticas do sexo, estratégias de vida e subjetividades: mulheres e agência no mercado do sexo e no circuito de turismo internacional no Ceará. Dissertação de mestrado, Programa de Sociologia, Universidade Federal de Pernambuco, 2013.

RIBEIRO, Manuela e SACRAMENTO, Octávio. Findings of Research in the Spanish-Portuguese Frontier. European Journal of Women's Studies, vol. 12 (1), 2005, pp.61-81.

SHARMA, Aradhana e GUPTA, Akhil. Introduction. In: The Anthropology of the State, a Reader. Oxford, Blackwell Publishing, 2006, pp.1-43.

Silva, Ana Paula e BlanchetTe, Thaddeus. "Nossa Senhora da Help": sexo, turismo e deslocamento transnacional em Copacabana. Cadernos Pagu (25), Núcleo de Estudos de Gênero - Pagu/Unicamp, 2005, pp.249-281.

Silva, Ana Paula da; Blanchette, Thaddeus Gregory; Bento, Andressa Raylane. Cinderella Deceived: Analyzing a Brazilian Myth Regarding 
Trafficking in Persons. Vibrant - Virtual Brazilian Anthropology, vol. 10, $\mathrm{n}^{\circ}$ 2, Brasília, ABA jul-dez 2013, pp. 378-419. Disponível em: $<$ http://www.vibrant.org.br/issues/v10n2/ana-paula-da-silvathaddeus-gregory-blanchette-andressa-raylane-bento-cinderelladeceived $/>$.

SiLVA, Hélio R. S. Travesti, a invenção do feminino. Rio de Janeiro, Relumé- Dumará, 1993.

SIMÕES, Soraya Silveira. Vila Mimosa, etnografia da cidade cenográfica da prostituição carioca. Rio de Janeiro, Editora da UFF, 2010.

SIMÕES, Soraya Silveira. Identidade e política: a prostituição e o reconhecimento de um métier no Brasil. R@U, Revista de Antropologia Social dos alunos do PPGAs, São Carlos, vol 2-1, 2010b, pp.24-46.

SKACKAUSKAS, Andreia: Prostituição, gênero e direitos: noções e tensões nas relações entre prostitutas e Pastoral da Mulher Marginalizada. Tese de Doutorado. Programa de Doutorado em Ciências Sociais. Universidade Estadual de Campinas, 2014.

SouSA, Ilnar de. O cliente, o outro lado da prostituição. AnnaBlume, São Paulo, 1998.

StOEBENAU, Kirsten et alii. More than just talk: the framing of transactionalsex and its implications for vulnerability to HIV in Lesotho, Madagascar and South Afric. Globalization and Health 7:34, 2011.

Disponivel em: $<$ http://www.globalizationandhealth.com/content/7/1/34>.

TAVARES, Aline Godoi de Castro: A organização da zona: notas etnográficas sobre relações de poder na zona de prostituição Jardim Itatinga, Campinas - SP. Dissertação de mestrado. Programa de Antropologia Social, Universidade Estadual de Campinas, 2014.

TEDESCO, Leticia. Explorando o negócio do sexo: uma etnografia sobre as relações afetivas e comerciais entre prostitutas e agenciadores em Porto Alegre. Dissertação de mestrado, UFRGS, 2008.

TEDESCO, Leticia. Atores sociais na batalha: estigma e cidadania entre prostitutas através de uma ONG em Porto Alegre. TCC, UFRGS, 2005.

TeIXEIRA, Flávia do Bonsucesso. L'Italia dei Divieti: entre o sonho de ser européia e o babado da prostituição. Cadernos Pagu (31), Campinas- 
SP, Núcleo de Estudos de Gênero-Pagu/Unicamp, 2008. Disponível em: <http://dx.doi.org/10.1590/S0104-83332008000200013>.

ToGnI, Paula Christofoletti. A Europa é o Cacém. Mobilidades, gênero e sexualidade nos deslocamentos de jovens brasileiros para Portugal. Tese de Doutoramento em Antropologia. ISCTE/OUL, Lisboa, 2014.

Zelizer, Viviana. La negociación de la intimidad. México, Fondo de Cultura Económica, 2009. 